\title{
Preparation of $\mathrm{Sn}_{3} \mathrm{O}_{4}$ Modified Ti/Black $\mathrm{TiO}_{2}$ Electrode with Enhanced Photoelectrocatalytic Performance for Water Remediation
}

\author{
Zeqi Jiang ${ }^{\dagger}$, Jian Zhang ${ }^{\dagger}$, Wenfeng Li, Pengyuan Wang ${ }^{*}$, Guowen Wang, \\ Hongchao Ma and Yinghuan Fu* \\ School of Light Industry \& Chemical Engineering, Dalian Polytechnic University, No. 1 \\ Qinggongyuan, Ganjingzi District, Dalian, 116034, People's Republic of China \\ *E-mail: wangpengyuan@ dlpu.edu.cn, fuyinghuan@ sina.com \\ †The first two authors contributed equally to this paper
}

Received: 2 November 2021 / Accepted: 10 December 2021 / Published: 5 January 2022

Bio-refractory wastewater from the dyeing and finishing process has become a critical environmental problem. Semiconductor photoelectrocatalytic (PEC) technology is one of the most effective methods to remove organic pollutants from effluents, while the performance of photoanodes can significantly affect degradation efficiency. Herein, novel heterostructure composite photoanodes were synthesized through assembling various amounts of $\mathrm{Sn}_{3} \mathrm{O}_{4}$ nanosheets on the hydrogenated $\mathrm{TiO}_{2}$ sheets to degrade the Reactive Brilliant Blue KN-R (RBB KN-R) solution. The hydrogenation expanded the optical absorption range improving the utilization of sunlight. And the incorporation of $\mathrm{Sn}_{3} \mathrm{O}_{4}$ nanosheets increases the electrochemically active area, promotes interfacial carrier transport, enhances interfacial carrier transport and facilitates the generation of reactive radicals during PEC. The composite electrode $\left(\mathrm{Sn}_{3} \mathrm{O}_{4}-\mathrm{Ti} / \mathrm{b}-\mathrm{TiO}_{2}\right)$ showed excellent degradation performance over $85 \%$ degradation of (RBB KN-R within 120 min and quite stable in 5 degradation cycles, holding great promise in accelerated degradation of dyeing wastewater.

Keywords: Heterostructure, Water remediation, Photoelectrocatalysis, $\mathrm{Sn}_{3} \mathrm{O}_{4}$,

\section{$\underline{\text { FULL TEXT }}$}

(C) 2022 The Authors. Published by ESG (www.electrochemsci.org). This article is an open access article distributed under the terms and conditions of the Creative Commons Attribution license (http://creativecommons.org/licenses/by/4.0/). 